\title{
Pro: Are we ready to translate Alzheimer's disease modifying therapies to people with Down syndrome?
}

\author{
Michael S Rafii \\ See related debate by Head and Schmitt, http://alzres.com/content/6/5/61
}

\begin{abstract}
Background: Down Syndrome (DS) is caused by trisomy of chromosome 21, which includes the gene for the amyloid precursor protein (APP) and leads to overproduction of beta-amyloid. Clinical-pathological studies indicate that individuals with DS begin demonstrating Alzheimer's disease (AD) pathology during adolescence and that 100\% exhibit such changes by age 40. Individuals with DS therefore represent a highly enriched population for AD. Additionally, owing to their baseline intellectual disability, people with DS represent a more vulnerable group of individuals as compared with other populations. Given the recent developments in AD biomarkers, combined with the prospect of achieving greater efficacy with earlier therapeutic intervention, it is logical to include adults with DS in prevention trials for AD.

Discussion: The US Food and Drug Administration has released draft guidance on drug development for early-stage $A D$, based on the understanding that $A D$ is a progressive disease with symptoms developing decades after the disease process has begun. New biomarkers now permit detection of AD pathology in asymptomatic individuals such that there now exists an opportunity to conduct clinical trials of potentially disease-modifying drugs in the earliest stages of the disease and perhaps have the greatest chance of demonstrating efficacy. As such, clinical trials are being actively planned or conducted in individuals with causative mutations in the APP, presenilin-1 (PSEN1), and presenilin-2 (PSEN2) genes.

Summary: Individuals with DS comprise perhaps the largest group of people with genetically determined AD, with a worldwide population of about 6 million people. Only by inclusion can we provide access to rational therapies that offer the greatest chance of benefiting this highly at-risk population.
\end{abstract}

\section{Introduction}

\section{Preclinical Alzheimer's disease}

Converging evidence from longitudinal studies of clinically normal older and familial Alzheimer's disease (AD) cohorts strongly suggests that the AD pathophysiological process begins decades before the manifestation of clinical dementia. Recent advances in biomarkers, including amyloid positron emission tomography (PET), Tau PET, and volumetric magnetic resonance imaging (MRI), and cerebrospinal fluid studies permit presymptomatic detection of $\mathrm{AD}$ pathology. Hypothetical models have been proposed in which these biomarkers become increasingly

Correspondence: mrafii@ucsd.edu

Department of Neurosciences, University of California, San Diego, 9500 Gilman Drive, MC 0949, La Jolla, CA 92093, USA abnormal in an ordered manner as the disease progresses and symptoms emerge [1]. Longitudinal studies of familial $\mathrm{AD}$ have provided substantial support for and refinement of such models $[2,3]$.

Mutations of all genes known to be involved in familial AD - presenilin-1 (PSEN1), PSEN2, and amyloid precursor protein $(A P P)$ - contribute to increased absolute or relative production of the 42 -amino-acid-length cleavage product of APP, beta-amyloid (A $\beta)$, which is the main constituent of the amyloid plaques that characterize AD [4]. This tight link between genetic determinants of $\mathrm{AD}$ and the overproduction of $A \beta$ is compelling support for the amyloid hypothesis and has been the focal point in the development of disease-modifying drugs for $\mathrm{AD}$. 
Presumably, disease-modifying treatments should begin prior to the onset of cognitive symptoms and before extensive neurodegeneration has occurred. A decade of negative anti-amyloid trials in mild to moderate AD supports the notion that disease-modifying treatment in the dementia stage may simply be too late. The field of $\mathrm{AD}$ drug development has therefore steadily marched earlier and earlier in the disease continuum, evaluating antiamyloid treatments in prodromal $\mathrm{AD}$ and, most recently, in preclinical AD. Although autosomal dominant mutation carriers represent less than $2 \%$ of all AD cases, such cohorts are now being intensely studied in secondary prevention trials of $\mathrm{AD}$ using anti-amyloid drugs, given the opportunity they afford for presymptomatic intervention.

\section{Discussion}

\section{Down syndrome is preclinical Alzheimer's disease}

Down syndrome (DS), or trisomy 21, affects 400,000 people in the US and has an incidence of 1 out of 691 live births [5]. It is caused by meiotic non-disjunction, leading to an extra copy of chromosome 21, on which the APP gene resides. Consequently, there is increased APP mRNA and protein expression as well as higher levels of $A \beta$ [6]. Because of this overproduction of $A \beta$, by the age of 40 , virtually all people with DS show the same neuropathological changes as is seen in AD [7]. Moreover, the cholinergic losses seen in the brains of individuals with DS are identical to those observed in AD [8]. In contrast to sporadic $\mathrm{AD}$, however, amyloid plaques and neurofibrillary tangles in DS start developing in people as early as 12 years of age [9].

Recent data also indicate that AD biomarker changes in DS are similar to those observed in familial and sporadic $A D$. There is a sixfold increase in plasma $A \beta$ in individuals with DS as compared with age-matched nonDS individuals [10]. Results of amyloid PET imaging from individuals with DS are also consistent with those seen in non-DS individuals with AD [11]. And, as in familial and sporadic $\mathrm{AD}$, the presence of the apolipoprotein $\mathrm{E}$ $\varepsilon 4$ allele is associated with greater accumulation of $A \beta$ protein in the brains of adults with DS [12] and greater risk of an earlier age of onset of dementia [13]. The link between triplication of the APP gene and subsequent overproduction of $A \beta$ leading to $A D$ dementia in $D S$ is further supported by the case of a DS individual with partial trisomy of chromosome 21 who was disomic for the APP gene and who did not develop dementia or any AD pathology [14].

Postmortem studies also indicate that adults with DS have the same prominent pattern of cerebral atrophy involving the medial temporal lobe structures as has been reported in the early stages of familial and sporadic AD [15]. Volumetric MRI studies of age-related brain changes in DS demonstrate the same pattern of hippocampalspecific atrophy observed in AD. Furthermore, the hippocampal atrophy in DS correlates with changes in memory measures [16].

In DS, in which intellectual disability is lifelong, the question arises as to how changes in cognition and functioning can be reliably related to the emergence of $\mathrm{AD}$ symptomatology. It should be noted that baseline intellectual disability in DS is relatively static. Results from recent biomarker studies suggest that these techniques may be able to accurately discriminate progressive brain changes due to AD age-related changes in DS. Moreover, DS individuals who are over 40 years old show cognitive decline in somewhat discrete phases. Initially, there is an isolated, slowly progressive memory decline [17], analogous to the mild cognitive impairment stage of $\mathrm{AD}$ in the sporadic population, in which memory loss is the earliest neuropsychological deficit. This phase is followed by a decline in other cognitive functions and is coincident with functional decline and dementia onset [17]. Thus, older adults with DS represent a population in which the neuropsychological profile of cognitive change due to AD can be followed in conjunction with biomarker changes decades before dementia occurs.

\section{Imperative for Alzheimer's disease prevention in Down syndrome}

The number of older DS adults in the US is increasing. In fact, from 1979 through 2003, the prevalence of DS increased from 9.0 to 11.8 per 10,000 live births in 10 US regions [18]. This increase is due partially to the increase in the number of women who conceive after age 35 [19]. In addition, people with DS have experienced significant increases in life expectancy as a result of reduced institutionalization and improved access to medical care, such as surgical intervention for congenital heart defects [20]. With increased life expectancy, there has been an increase in the prevalence of older DS adults with dementia. It is currently estimated that there are over 200,000 people with DS over the age of 55 in the US [21]. Over $30 \%$ of DS adults more than 50 years old and over $50 \%$ of DS adults more than 60 years old have been diagnosed with AD dementia [22]. By the age of 70, approximately $75 \%$ of individuals with DS have dementia [23].

\section{Alzheimer's disease prevention trials in Down syndrome}

Given the high risk of people with DS developing AD, it is quite reasonable to consider prevention trials in this population. We have sufficient knowledge about AD to design and conduct secondary prevention studies in other genetically determined populations. Undeniably, there is more to learn about DS, but that does not preclude inclusion of this group in AD prevention trials in which the incidence and pathology of $\mathrm{AD}$ are well understood. One can envision a relatively small, earlystage study confirming feasibility and determining effect 
size in non-demented DS individuals to inform a larger late-stage trial. Variance in the rate of cognitive decline as well as signals on putative AD biomarkers in the initial phase of development would be used to calculate the sample size required, as well as the duration of treatment, for a definitive late-stage trial. Recent studies using amyloid PET imaging demonstrate that deposition of fibrillar amyloid is most dynamic between ages 35 and 55. This age range may be an appropriate window to assess antiamyloid therapeutics.

Ultimately, however, endpoints in AD prevention trials in DS will be cognitive outcomes as these will have the greatest translatability to clinical meaningfulness. The US Food and Drug Administration recently provided guidance on drug development for the treatment of preclinical AD [24]. This guidance indicates that an effect on a valid and reliable cognitive assessment used as a single primary efficacy measure would be considered for approval in the context of a patient with positive biomarkers of AD [25]. Instruments will need to be sensitive for detecting change over time in relation to age, baseline performance, and other participant characteristics. Such valid cognitive assessment tools currently exist for DS [26-28].

\section{Summary}

Multiple lines of evidence suggest that individuals with DS suffer exactly the same pathological process in later life as individuals with the other forms of AD. Indeed, there is little to distinguish the pathological changes in either condition. In DS, triplication of the APP gene leads to the overproduction of $A \beta$ and drives amyloidogenic pathways leading to plaques, tangles, and neurodegeneration. Owing to the $100 \%$ prevalence of $\mathrm{AD}$ pathology in adults with DS, individuals with DS represent a well-defined subgroup of predetermined AD. With 6 million people worldwide, DS is the largest population of predictable AD cases. By including individuals with DS in prevention trials, there is an opportunity to provide access to potentially disease-altering therapies to this highly at-risk population.

\footnotetext{
Abbreviations

Aß: Beta-amyloid; AD: Alzheimer's disease; APP: Amyloid precursor protein; DS: Down syndrome; MRI: Magnetic resonance imaging; PET: Positron emission tomography.

\section{Competing interests}

MSR has received research grants from Elan Corporation (Dublin, Ireland), Hoffmann-La Roche (Basel, Switzerland), Janssen Pharmaceuticals (Titusville, New Jersey), Genentech (South San Francisco, CA, USA), Eli Lilly and Company (Indianapolis, IN, USA), Accera (Broomfield, CO, USA), Merck (Whitehouse Station, NJ, USA), and Bristol-Myers Squibb (New York City, NY, USA). He has served as a consultant to Novartis (Basel, Switzerland).
}

Published online: 12 September 2014

\section{References}

1. Jack CR Jr, Knopman DS, Jagust WJ, Shaw LM, Aisen PS, Weiner MW, Petersen RC, Trojanowski JQ: Hypothetical model of dynamic biomarkers of the Alzheimer's pathological cascade. Lancet Neurol 2010, 9:119-128.

2. Bateman RJ, Xiong C, Benzinger TL, Fagan AM, Goate A, Fox NC, Marcus DS, Cairns NJ, Xie X, Blazey TM, Holtzman DM, Santacruz A, Buckles V, Oliver A, Moulder K, Aisen PS, Ghetti B, Klunk WE, McDade E, Martins RN, Masters CL, Mayeux R, Ringman JM, Rossor MN, Schofield PR, Sperling RA, Salloway S, Morris JC, Dominantly Inherited Alzheimer Network: Clinical and biomarker changes in dominantly inherited Alzheimer's disease. N Engl J Med 2012, 367:795-804.

3. Reiman EM, Quiroz YT, Fleisher AS, Chen K, Velez-Pardo C, Jimenez-Del-Rio M, Fagan AM, Shah AR, Alvarez S, Arbelaez A, Giraldo M, Acosta-Baena N, Sperling RA, Dickerson B, Stern CE, Tirado V, Munoz C, Reiman RA, Huentelman MJ, Alexander GE, Langbaum JB, Kosik KS, Tariot PN, Lopera F: Brain imaging and fluid biomarker analysis in young adults at genetic risk for autosomal dominant Alzheimer's disease in the presenilin 1 E280A kindred: a case-control study. Lancet Neurol 2012, 11:1048-1056.

4. Scheuner D, Eckman C, Jensen M, Song X, Citron M, Suzuki N, Bird TD, Hardy J, Hutton M, Kukull W, Larson E, Levy-Lahad E, Viitanen M, Peskind E, Poorkaj P, Schellenberg G, Tanzi R, Wasco W, Lannfelt L, Selkoe D, Younkin S: Secreted amyloid beta-protein similar to that in the senile plaques of Alzheimer's disease is increased in vivo by the presenilin 1 and 2 and APP mutations linked to familial Alzheimer's disease. Nat Med 1996, 2:864-870.

5. Parker SE, Mai CT, Canfield MA, Rickard R, Wang Y, Meyer RE, Anderson P, Mason CA, Collins JS, Kirby RS, Correa A, National Birth Defects Prevention Network: Updated national birth prevalence estimates for selected birth defects in the United States, 2004-2006. Birth Defects Res A 2010, 88:1008-1016.

6. Schupf N, Sergievsky GH: Genetic and host factors for dementia in Down's syndrome. Br J Psychiatry 2002, 180:405-410.

7. Glenner GG, Wong CW: Alzheimer's disease and Down's syndrome: sharing of a unique cerebrovascular amyloid fibril protein. Biochem Biophys Res Commun 1984, 122:1131-1135.

8. Yates CM, Simpson J, Maloney AF, Gordon A, Reid AH: Alzheimer-like cholinergic deficiency in Down syndrome. Lancet 1980, 2:979.

9. Lemere CA, Blusztajn JK, Yamaguchi H, Wisniewski T, Saido TC, Selkoe DJ: Sequence of deposition of heterogeneous amyloid beta-peptides and APO E in Down syndrome: implications for initial events in amyloid plaque formation. Neurobiol Dis 1996, 3:16-32.

10. Schupf N, Patel B, Silverman W, Zigman WB, Zhong N, Tycko B, Mehta PD, Mayeux R: Elevated plasma amyloid beta-peptide 1-42 and onset of dementia in adults with Down syndrome. Neurosci Lett 2001, 301:199-203.

11. Handen BL, Cohen AD, Channamalappa U, Bulova P, Cannon SA, Cohen WI, Mathis CA, Price JC, Klunk WE: Imaging brain amyloid in nondemented young adults with Down syndrome using Pittsburgh compound B. Alzheimers Dement 2012, 8:496-501.

12. Hyman BT, West HL, Rebeck GW, Lai F, Mann DM: Neuropathological changes in Down's syndrome hippocampal formation. Effect of age and apolipoprotein E genotype. Arch Neurol 1995, 52:373-378.

13. Schupf N, Kapell D, Lee JH, Zigman W, Canto B, Tycko B, Mayeux R: Onset of dementia is associated with apolipoprotein E epsilon4 in Down's syndrome. Ann Neurol 1996, 40:799-801.

14. Prasher VP, Farrer MJ, Kessling AM, Fisher EM, West RJ, Barber PC, Butler AC: Molecular mapping of Alzheimer-type dementia in Down's syndrome. Ann Neurol 1998, 43:380-383.

15. Hof PR, Bouras C, Perl DP, Sparks DL, Mehta N, Morrison JH: Age related distribution of neuropathologic changes in the cerebral cortex of patients with Down's syndrome: quantitative regional analysis and comparison with Alzheimer's disease. Arch Neurol 1995, 52:379-391.

16. Krasuski JS, Alexander GE, Horwitz B, Rapoport SI, Schapiro MB: Relation of medial temporal lobe volumes to age and memory function in nondemented adults with Down's syndrome: implications for the prodromal phase of Alzheimer's disease. Am J Psychiatry 2002, 159:74-81.

17. Haxby JV, Schapiro MB: Longitudinal Study of Neuropsychological Function in Older Adults with Down Syndrome. In Down Syndrome and Alzheimer's Disease. Edited by Nadel L, Epstein CJ. New York: Wiley-Liss; 1992:35-50. 
18. Shin M, Besser LM, Kucik JE, Lu C, Siffel C, Correa A, Congenital Anomaly Multistate Prevalence and Survival Collaborative: Prevalence of Down syndrome among children and adolescents in 10 regions of the United States. Pediatrics 2009, 124:1565-1571.

19. Zigman WB: Atypical aging in Down syndrome. Dev Disabil Res Rev 2013, 18:51-67.

20. Yang Q, Rasmussen SA, Friedman JM: Mortality associated with Down's syndrome in the US from 1983 to 1997: a population-based study. Lancet 2002, 359:1019-1025.

21. Silverman W, Zigman WB, Kim H, Krinsky-McHale S, Wisniewski HM: Aging and dementia among adults with mental retardation and Down syndrome. Topic Geriatr Rehabil 1998, 13:49-64.

22. Prasher VP, Filer A: Behavioural disturbance in people with Down's syndrome and dementia. J Intellect Disabil Res 1995, 39:432-436.

23. Zigman WB, Schupf N, Devenny DA, Miezejeski C, Ryan R, Urv TK, Schubert R, Silverman W: Incidence and prevalence of dementia in elderly adults with mental retardation without Down syndrome. Am J Ment Retard 2004, 109:126-141.

24. Center for Drug Evaluation and Research: Guidance for Industry: Alzheimer's Disease: Developing Drugs for the Treatment of Early Stage Disease. Washington, DC: Department of Health and Human Services, Food and Drug Administration; 2013.

25. Kozauer N, Katz R: Regulatory innovation and drug development for early-stage Alzheimer's disease. N Engl J Med 2013, 368:1169-1171.

26. Oliver C, Crayton L, Holland A, Hall S, Bradbury J: A four year prospective study of age-related cognitive change in adults with Down's syndrome. Psychol Med 1998, 28:1365-1377.

27. Hon J, Huppert FA, Holland AJ, Watson P: Neuropsychological assessment of older adults with Down's syndrome: an epidemiological study using the Cambridge Cognitive Examination (CAMCOG). Br J Clin Psychol 1999, 38:155-165.

28. Devenny DA, Krinsky-McHale SJ, Sersen G, Silverman WP: Sequence of cognitive decline in dementia in adults with Down's syndrome. J Intellect Disabil Res 2000, 44:654-665.

doi:10.1186/s13195-014-0060-7

Cite this article as: Rafii: Pro: Are we ready to translate Alzheimer's

disease modifying therapies to people with Down syndrome?

Alzheimer's Research \& Therapy 2014 6:60. 